\title{
Erratum to Giant right coronary artery aneurysm complicated by acute myocardial infarction
}

\author{
Hitoshi Kanamitsu, MD · Hidenori Yoshitaka, MD \\ Masahiko Kuinose, MD • Yoshimasa Tsushima, MD
}

(C) The Japanese Association for Thoracic Surgery 2010
Erratum to: Gen Thorac Cardiovasc Surg (2010) 58:186-189
DOI 10.1007/s11748-009-0478-1

The header on all pages of the article should read:

Gen Thorac Cardiovasc Surg (2010) 58:186-189

instead of

Gen Thorac Cardiovasc Surg (2009) 57:186-189

The copyright line on the first page of the article should read:

The Japanese Association for Thoracic Surgery 2010

instead of

The Japanese Association for Thoracic Surgery 2009

The publisher sincerely apologizes for any inconvenience these errors may have caused.

\footnotetext{
This online version of the original article can be found at http://dx.doi.org/10.1007/s11748-009-0478-1.

H. Kanamitsu $(\bowtie) \cdot$ H. Yoshitaka $\cdot$ M. Kuinose $\cdot$ Y. Tsushima Department of Cardiovascular Surgery, The Sakakibara Heart Institute of Okayama, Marunouchi 2-1-10, Okayama 700-0823, Japan

Tel. +81-86-225-7111; Fax +81-86-223-5265

e-mail; hitoshi_k_1020@hotmail.com
} 